\title{
Differential Determination of Organic Mercury, Mercury(II) Oxide and Mercury(II) Sulfide in Sediments by Cold Vapor Atomic Absorption Spectrometry
}

\author{
Hayao SaKamoto, Takashi TomiYasu and Norinobu YoneHARA
}

\author{
Department of Chemistry, Faculty of Science, Kagoshima University, Kagoshima 890, Japan
}

\begin{abstract}
A method has been proposed for the differential determination of mercury compounds in sediments, based on their successive extraction followed by a cold vapor atomic absorption spectrometric (CVAAS) determination. Organic mercury was first extracted by shaking a sediment sample with chloroform. The mercury in the extract was subsequently back-extracted into a $0.01 \mathrm{M}$ sodium thiosulfate solution. In order to separate mercury(II) oxide from mercury(II) sulfide, the residue was treated with $0.05 \mathrm{M}$ sulfuric acid so as to extract only mercury(II) oxide. Mercury(II) sulfide was finally extracted from the residue with $1 \mathrm{M}$ hydrochloric acid containing 3\% sodium chloride in the presence of copper(I) chloride. The mercury in each extract was determined by CVAAS. When artificial standard sediment samples spiked with a given amount of each mercury compound were successively treated by the above-mentioned procedures, the recoveries of organic mercury, mercury(II) oxide and mercury(II) sulfide were $99.9,99.5$ and $98.2 \%$, respectively. This method was successfully applied to a differential determination of mercury compounds in marine sediments.
\end{abstract}

Keywords Differential determination, mercury determination, cold vapor atomic absorption spectrometry, selective extraction, sediment

Mercury is widely distributed in nature, circulating among several media, and occuring in different chemical forms which show various toxicities. In addition, it has been recognized that inorganic mercury is converted into a more toxic organic mercury compound by organisms during natural cycles. Therefore, it is required not only to determine the total amount of mercury, but also to identify and quantify its chemical forms in environmental samples. Various methods based on gas chromatography ${ }^{1-4}$, cold vapor atomic absorption spectrometry

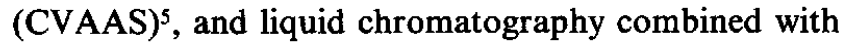
CVAAS $^{6}$ have been developed for differential determinations of mercury compounds in water samples. The speciation of mercury compounds in biological materials has also been achieved by gas chromatography combined with graphite furnace atomic absorption spectrometry. ${ }^{7}$ Sediments are one of the most interesting types of environmental samples. Regarding sediments, however, attention has mainly been focused on organic mercury, and there are only a few methods ${ }^{8}$ available for a differential determination of organic mercury and inorganic mercury in sediment samples.

The present paper describes the differential determination of organic mercury, mercury(II) oxide and mercury(II) sulfide based on a successive extraction of these mercury compounds with chloroform, a $0.05 \mathrm{M}$ sulfuric acid solution and a $1 \mathrm{M}$ hydrochloric acid solution containing $3 \%$ sodium chloride, respectively, followed by a CVAAS determination. This method was applied to marine sediments with satisfactory results.

\section{Experimental}

\section{Apparatus}

The Rigaku Mercury SP $^{9}$ used comprised an electric furnace, a mercury trapping room, an air pump for delivering carrier gas, a multipass-auto valve and an atomic absorption spectrometer. Air was used as the carrier gas, fed through an activated charcoal-filled tube. A sample placed on a porcelain boat was heated in the furnace at $c a .300^{\circ} \mathrm{C}$ for $3 \mathrm{~min}$, and then at $c a .700^{\circ} \mathrm{C}$ for $6 \mathrm{~min}$ in order to complete the decomposition; the generated gases containing mercury were swept away by the carrier gas to the mercury trapping room, where the mercury vapor was trapped on a porous gold collector, while the other combustion gases passed through to waste. After heating the porous gold collector at ca. $700^{\circ} \mathrm{C}$, the liberated mercury vapor was introduced into a quartz cell, in which the atomic absorption of mercury was measured at $253.7 \mathrm{~nm}$. These operations were performed automatically.

The porcelain boat used was heated at $c a .800^{\circ} \mathrm{C}$ for $2 \mathrm{~h}$ in an electric furnace in order to remove any memory 
effect of mercury.

\section{Reagents}

All reagents were of analytical-reagent grade. $\mathrm{Pu}-$ rified water was prepared with a Millipore Milli-Q water purification system.

Distilled chloroform was used.

A stock standard mercury(II) solution (1000 $\left.\mathrm{mg} \mathrm{l}^{-1}\right)$ was prepared by dissolving $1.354 \mathrm{~g}$ of mercury(II) chloride in $10 \mathrm{ml}$ of $5 \mathrm{M}$ sulfuric acid and diluting to exactly 11 with water. This solution was stored in a brown glass bottle.

A working standard mercury(II) soluion $\left(0.10 \mathrm{mg} \mathrm{l}^{-1}\right)$ was prepared by appropriate dilution of the stock solution with $0.05 \mathrm{M}$ sulfuric acid containing $3.0 \%$ sodium chloride. In the presence of both sulfuric acid and chloride ions, mercury(II) ions were kept stable in the solution. This working standard solution was stored in a brown glass bottle.

A sodium thiosulfate solution $(0.01 \mathrm{M})$ was prepared by dissolving $2.482 \mathrm{~g}$ of sodium thiosulfate in water and diluting to 11 with water.

Sodium chloride and activated alumina were heated at ca. $700^{\circ} \mathrm{C}$ for $2 \mathrm{~h}$ in an electric furnace in order to remove any trace of mercury.

An addition agent was prepared by mixing calcium hydroxide and sodium carbonate, which were previously ignited at $c a .700^{\circ} \mathrm{C}$ for $2 \mathrm{~h}$ in a $1: 1$ volume ratio.

Since no suitable standard reference materials of sediments containing several mercury compounds of known amounts are available, spiked standard samples were prepared as follows: a known amount of each mercury compound was added to finely powdered and homogenized soil, which was made mercury-free by previous heating at $c a .700^{\circ} \mathrm{C}$ for $2 \mathrm{~h}$.

\section{Procedures}

Procedure-tot $\cdot \mathrm{Hg}$ (for determination of total mercury): activated alumina was first laid on the bottom of a porcelain boat; a suitable amount $(0.01-0.1 \mathrm{~g})$ of a sediment sample containing $0.1-10 \mathrm{ng}$ of mercury was then put on it. In case of liquid samples, a suitable aliquot $(<200 \mu \mathrm{l})$ containing less than $10 \mathrm{ng}$ of mercury was pipetted onto activated alumina. After the sample was covered with $c a .2 \mathrm{~g}$ of the addition agent, the porcelain boat was placed into the furnace of the mercury analyzer and the mercury content was automatically measured by CVAAS.

Since samples with a high mercury content $\left(>1 \mu \mathrm{g} \mathrm{g}^{-1}\right)$ cause serious contamination of the instrument that influences the subsequent measurment of samples with a low mercury content, such samples were heated at ca. $700^{\circ} \mathrm{C}$ together with the addition agent and the generated mercury vapor was once trapped into $20 \mathrm{ml}$ of potassium permanganate solution $(0.04 \%)$ acidified with sulfuric acid $(0.75 \mathrm{M})$. After $0.5 \mathrm{ml}$ of a $20 \%$ hydroxylamine hydrochloride solution was added to the trapping solution so as to reduce any excess of permanganate and the solution was made up to $50 \mathrm{ml}$ with water, a suitable aliquot of the resulting solution was subjected to the mercury analyzer. Details of this procedure were described previously. ${ }^{10}$

Procedure-org $\cdot \mathrm{Hg}$ (for separation and determination of organic mercury): to a sediment sample $(1-5 \mathrm{~g})$ in a $50 \mathrm{ml}$ glass centrifuge tube, $20 \mathrm{ml}$ of chloroform was added. The tube was stoppered, shaken in a shaker for $2 \mathrm{~min}$, and then centrifuged at 3000 r.p.m. for $2 \mathrm{~min}$. The chloroform phase was transferred into a separatory funnel. The extraction was repeated with another $20 \mathrm{ml}$ of chloroform. To the combined chloroform extract in the separatory funnel, $3.0 \mathrm{ml}$ of $0.01 \mathrm{M}$ sodium thiosulfate solution was added and shaken for $2 \mathrm{~min}$. Mercury in the aqueous phase was then determined by Procedure-tot $\cdot \mathrm{Hg}$. The residue in the centrifuge tube was used for the subsequent procedures.

Procedure-HgO (for separation and determination of mercury(II) oxide): after the centrifuge tube was left unstoppered so as to evaporate the residual chloroform to dryness, $10 \mathrm{ml}$ of a $0.05 \mathrm{M}$ sulfuric acid was added to the residue in the centrifuge tube. The centrifuge tube was then stoppered, shaken in a shaker for 2 min and finally centrifuged at 3000 r.p.m. for $2 \mathrm{~min}$. The mercury in the supernatant was determined by Procedure-tot $\cdot \mathrm{Hg}$.

Procedure-HgS (for separation and determination of mercury(II) sulfide): to the residue in the centrifuge tube, $0.5 \mathrm{~g}$ of copper(I) chloride and $20 \mathrm{ml}$ of $1 \mathrm{M}$ hydrochloric acid containing $3 \%$ sodium chloride were added. The centrifuge tube was then stoppered, shaken in a shaker for $10 \mathrm{~min}$ and finally centrifuged at 3000 r.p.m. for 2 min. The supernatant was transferred into a volumetric flask. The extraction was repeated three times with additional $20 \mathrm{ml}$ aliquots of $1 \mathrm{M}$ hydrochloric acid containing $3 \%$ sodium chloride. The combined supernatant was diluted to $100 \mathrm{ml}$ with water and subjected to mercury determination (Procedure-tot $\cdot \mathrm{Hg}$ ).

Procedure-rsd $\cdot \mathrm{Hg}$ (for determination of residual mercury): the residue in the centrifuge tube was dried at ca. $45^{\circ} \mathrm{C}$ for several hours; the mercury was determined by Procedure-tot $\cdot \mathrm{Hg}$.

Procedure-acid $\cdot \mathrm{L}$ (for determination of organic mercury by acid leaching): a sediment sample was first treated with two $20 \mathrm{ml}$ portions of $1 \mathrm{M}$ hydrochloric acid containing $3 \%$ sodium chloride in the presence of $0.5 \mathrm{~g}$ of copper(I) chloride; the conditions were the same as in Procedure-HgS. The resultant solution was then treated according to Procedure-org. $\mathrm{Hg}$, except that $10 \mathrm{ml}$ portions of chloroform were used.

\section{Preparation of a calibration curve}

For a calibration curve, $10-100 \mu \mathrm{l}$ aliquots of the working standard solution $\left(0.10 \mathrm{mg} \mathrm{l}^{-1}\right)$ were analyzed by Procedure-tot $\cdot \mathrm{Hg}$. The detection limit was $0.1 \mathrm{ng}$ of mercury and the linear range was $0-20 \mathrm{ng}$ of mercury. 


\section{Results and Discussion}

\section{Choice of the extracting solvent for mercury compounds}

Although several acid/oxidant digestion procedures have been widely used for solid samples, these procedures are only adequate for the determination of the total mercury, and are unsuitable for the selective determination of different mercury compounds. In the present work, it was first examined which mercury compound was extractable into each of the following solvents from sediment samples: three acid solutions (hydrochloric acid, nitric acid and sulfuric acid) and two organic solvents (benzene and chloroform). With all three acid solutions, mercury(II) oxide was quantitatively extracted and methyl mercury chloride was partially extracted. Although the addition of copper(I) chloride caused a quantitative extraction of methyl mercury chloride, it was accompanied by the extraction of mercury sulfide. Therefore, the quantitative separation of the inorganic species with acids alone was not possible.

Both the organic solvents extracted quantitatively only methyl mercury chloride; chloroform gave a lower blank and more reproducible results than benzene (the readings of analyzer for the blank were 0.4 with chloroform and 1.0 with benzene, and the recoveries for $0.100 \mathrm{ppm}$ spiked mercury were $0.093,0.097$ and $0.098 \mathrm{ppm}$ with chloroform and $0.13,0.16$ and $0.15 \mathrm{ppm}$ with benzene). Chloroform was therefore chosen as a suitable solvent for first separating organic mercury compounds. It is undesirable to subject chloroform solutions to the mercury analyzer, because of damage produced by the gases generated due to the thermal decomposition of chloroform. Back-extraction into a sodium thiosulfate solution prior to analysis was performed.

\section{Back-extraction of organic mercury from chloroform into an aqueous solution}

The effect of the amount of a $0.01 \mathrm{M}$ thiosulfate solution on the back-extraction of mercury from chloroform into the aqueous phase was examined. A $40 \mathrm{ml}$ aliquot of chloroform spiked with a given amount $(0.10 \mathrm{mg}$ as $\mathrm{Hg})$ of methyl mercury chloride was taken into a separatory funnel. After the mercury compound was extracted with two $x \mathrm{ml}(x=2,3,4,5,10$ and 20) portions of the thiosulfate solution, the mercury content in each of the first and second extracts was determined by Procedure-tot $\cdot \mathrm{Hg}$. The efficiency of the first extraction was more than $99 \%$ in all the volumes of the thiosulfate solution tested. The smaller was the volume of the thiosulfate solution, the higher became the mercury concentration in the extract. Although a smaller volume causes a higher sensitivity in the subsequent determination of mercury, the use of $2 \mathrm{ml}$ of the thiosulfate solution gave less reproducible results; $3 \mathrm{ml}$ of the solution was thus used in the recommended procedure.

The effect of the shaking time in the $1-10 \mathrm{~min}$ range was examined with $3 \mathrm{ml}$ of the thiosulfate solution.
These variations in the shaking time showed that a $1 \mathrm{~min}$ of shaking was sufficient for extraction. Thus, a $2 \mathrm{~min}$ shaking time was chosen as the recommended procedure.

\section{Extraction of organic mercury from sediment into chloro- form}

An artificial standard sediment sample spiked with a given amount $(0.10 \mathrm{mg}$ as $\mathrm{Hg})$ of methyl mercury chloride was shaken with successive 10 or $20 \mathrm{ml}$ portions of chloroform; any mercury extracted into chloroform was determined according to Procedure-org $\cdot \mathrm{Hg}$, except for the volumes of chloroform. In this case, the mercury determinations were made for each extract, and any mercury in the residue was also determined by Procedure-rsd $\cdot H g$. As can be seen in Table 1, two successive extractions with $20 \mathrm{ml}$ portions of this solvent were required for a complete extraction of methyl mercury chloride from the sediment samples. Both ethyl mercury chloride and phenyl mercury chloride were also extracted quantitatively with chloroform, and their recoveries obtained by Procedure-org $\cdot \mathrm{Hg}$ were 97.4 and $96.2 \%$, respectively.

The mercury compounds originally present in real sediments may be more highly associated with the silicate matrix of the sediment than with the spiked mercury compound in artificial sediment samples and may, thus, resist the extraction into an organic solvent. Hence, the extraction efficiency of organic mercury with chloroform was confirmed by comparing the results for real sediment samples obtained by Procedure-org $\cdot \mathrm{Hg}$ with those obtained by Procedure-acid $\cdot \mathrm{L}$, which is an acid-leaching procedure frequently used to determine organic mercury alone in a sediment. ${ }^{11}$ As can be seen in Table 2, both

Table 1 Extraction efficiency of methyl mercury chloride from a sediment sample into chloroform

\begin{tabular}{ccccc}
\hline \multirow{2}{*}{$\begin{array}{c}\text { Volume of } \\
\text { chloroform } / \mathrm{ml}\end{array}$} & \multicolumn{4}{c}{ Hg found $/ \mu \mathrm{g}$} \\
\cline { 2 - 4 } & Extract & Residue \\
\cline { 2 - 5 } & 1st & 2nd & 3rd & \\
\hline 10 & 90.3 & 3.7 & 0.3 & 0.068 \\
20 & 99.8 & 2.7 & 0.1 & 0.074 \\
\hline
\end{tabular}

a. $\mathrm{Hg}$ added, $100 \mu \mathrm{g}$.

Table 2 Comparison of the extraction of organic mercury from marine sediments by using chloroform (Procedureorg. $\mathrm{Hg}$ ) and hydrochloric acid in the presence of copper(I) chloride (Procedure-acid $\cdot \mathrm{L})\left(\mu \mathrm{g} \mathrm{g}^{-1}\right)$

\begin{tabular}{ccc}
\hline \multirow{2}{*}{ Sample $^{\mathrm{a}}$} & \multicolumn{2}{c}{ Procedure } \\
\cline { 2 - 3 } & -org·Hg & -acid $\cdot \mathrm{L}$ \\
\hline Y-1 & 0.010 & 0.012 \\
Y-2 & 0.033 & 0.033 \\
\hline
\end{tabular}

a. Taken in Yatsushiro Sea in 1975. 
procedures gave comparable results.

Chloice of acid solution for the separation of mercury(II) oxide and mercury(II) sulfide

Mercury(II) sulfide is slightly soluble in acid, whereas mercury(II) oxide is highly soluble. We tried to separate these two inorganic compounds based on their solubility difference. An artificial standard sediment sample spiked with a given amount $(10 \mathrm{mg}$ as $\mathrm{Hg})$ of mercury(II) sulfide was treated according to Procedure$\mathrm{HgO}$ by using different acid solutions in varying concentrations. Although $2.8-4 \mu \mathrm{g}$ mercury was determined in the hydrochloric acid solution, no mercury was detected from both the sulfuric acid $(0.025-0.5 \mathrm{M})$ and nitric acid $(0.05-1.0 \mathrm{M})$ solutions in the concentration ranges examined. In this work sulfuric acid was adopted.

The extraction of mercury(II) oxide into a sulfuric acid solution was examined using an artificial standard sediment sample spiked with a given amount $(10 \mathrm{mg}$ as $\mathrm{Hg}$ ) of mercury(II) oxide, according to Procedure-HgO by varying acid concentrations. Mercury(II) oxide was completely extracted into a sulfuric acid solution at concentrations higher than $0.05 \mathrm{M}$. Since complete extraction was obtained by shaking for $30 \mathrm{~s}$ with $10 \mathrm{ml}$ of a $0.05 \mathrm{M}$ sulfuric acid solution, $2 \mathrm{~min}$ was chosen as the shaking time.

Effects of the sodium chloride concentration and the amount of copper(I) chloride on the extraction of mercury(II) sulfide from sediment

As mentioned above, the presence of chloride and the addition of copper(I) chloride were effective for the extraction of mercury(II) sulfide with acid solutions.

The effect of the added amount of copper(I) chloride was examined by treating an artificial standard sediment

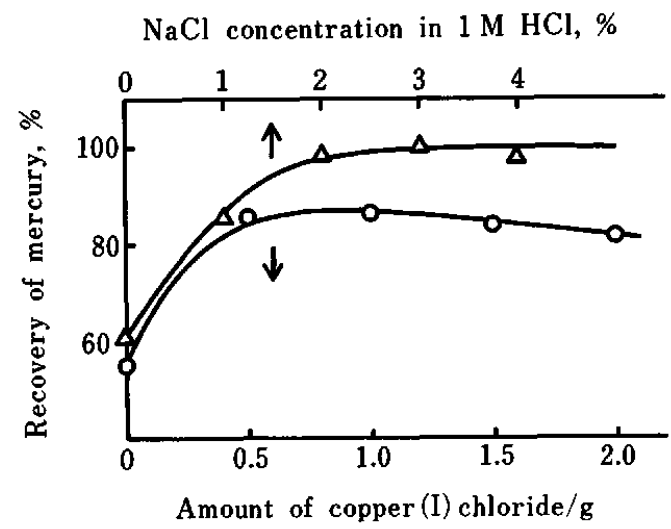

Fig. 1 Effect of amount of copper(I) chloride and concentration of sodium chloride on the extraction of mercury(II) sulfide. Mercury(II) sulfide added, $10 \mathrm{mg}$ as mercury; $(\mathrm{O})$ $1 \mathrm{M}$ hydrochloric acid containing $1 \%$ sodium chloride was used and other conditions (except for amount of copper(I) chloride) as in Procedure-HgS; $(\triangle)$ conditions (except for sodium chloride concentration) as in Procedure-HgS. sample spiked with a given amount $(10 \mathrm{mg}$ as $\mathrm{Hg})$ of mercury(II) sulfide, according to Procedure-HgS, except for the amounts of copper(I) chloride. In this case, $1 \mathrm{M}$ hydrochloric acid containing $1 \%$ sodium chloride was used. As can be seen in Fig. 1, maximum recovery was obtained in the range of $0.5-1 \mathrm{~g}$ copper(I) chloride. The addition of larger amounts caused lower recoveries. Part of the mercury(II) sulfide may be associated with copper(I) chloride which remained undissolved and, thus, partly maintained in the residue. We chose $0.5 \mathrm{~g}$ of copper(I) chloride for Procedure-HgS.

The effect of the sodium chloride concentration in $1 \mathrm{M}$ hydrochloric acid was also examined by treating the artificial standard sediment sample according to Procedure-HgS in different sodium chloride concentrations. The results obtained were also shown in Fig. 1. The presence of sodium chloride at concentrations higher than $2 \%$ gave complete extraction. A shaking time greater than $10 \mathrm{~min}$ was required for a complete extraction of mercury(II) sulfide.

\section{Separation of mercury compounds}

In order to check the efficacy of the procedures for the separation of the three mercury compounds-organic mercury, mercury(II) oxide and mercury(II) sulfide, the artificial standard sediment sample spiked with a given amount (10 $\mathrm{mg}$ as $\mathrm{Hg}$ ) of each of the mercury compounds was successively treated by Procedures-org. $\mathbf{H g},-\mathbf{H g O}$ and $-\mathrm{HgS}$. Table 3 shows that a nearly $100 \%$ recovery of each mercury compound was achieved by the appropriate procedures for the different chemical forms. The relative standard deviations for 4 replicate determinations were $\mathbf{0 . 2 8 \%}$ for methyl mercury chloride by Procedure-org. $\mathrm{Hg}, 1.3 \%$ for mercury(II) oxide by Procedure-HgO and $1.9 \%$ for mercury(II) sulfide by Procedure-HgS, respectively.

\section{Application to marine sediments}

In order to test the analytical applicability of this method, Procedure-org $\cdot \mathrm{Hg},-\mathrm{HgO},-\mathrm{HgS}$ and $-\mathrm{rsd} \cdot \mathrm{Hg}$ were applied to the differential determination of mercury compounds in real marine sediments. The sediment were dried at $c a .45^{\circ} \mathrm{C}$ for one week, and then finely ground in an agate mortar. Table 4 shows the results, together with those obtained by Procedure-tot $\cdot \mathrm{Hg}$. The sum of the four values obtained by Procedure-org $\cdot \mathrm{Hg}$,

Table 3 Separation efficiency of mercury compounds by Procedure-org. $\mathrm{Hg},-\mathrm{HgO}$ and $-\mathrm{HgS}$

\begin{tabular}{cccc}
\hline & \multicolumn{3}{c}{ Recovery, \% } \\
\cline { 2 - 4 } Mercury compound & \multicolumn{3}{c}{ Procedure } \\
& -org. $\mathrm{Hg}$ & $-\mathrm{HgO}$ & $-\mathrm{HgS}$ \\
\hline $\mathrm{MMC}^{\mathrm{a}}$ & 99.9 & 0.1 & 0.04 \\
$\mathrm{HgO}$ & 0.0 & 99.5 & 0.05 \\
$\mathrm{HgS}$ & 0.0 & 0.0 & 98.2 \\
\hline
\end{tabular}

a. Methyl mercury chloride. 
Table 4 Differential determination of mercury compounds in marine sediments

\begin{tabular}{|c|c|c|c|c|c|c|}
\hline \multirow{2}{*}{ Sample } & \multicolumn{6}{|c|}{ Mercury contents $/ \mu \mathrm{g} \mathrm{g}^{-1}$ as $\mathrm{Hg}$} \\
\hline & $\mathrm{org} \cdot \mathrm{Hg}$ & $\mathrm{HgO}$ & $\mathrm{HgS}$ & Residual $\mathbf{H g}$ & Sum of 4 values & Total $\mathrm{Hg}^{\mathrm{e}}$ \\
\hline $\mathbf{M}-1^{\mathbf{a}}$ & $0.36(1.3)^{d}$ & $0.29(1.0)$ & $24.9(89.6)$ & $2.2(7.9)$ & 27.8 & 26.7 \\
\hline $\mathrm{M}-2^{\mathrm{a}}$ & $0.35(1.1)$ & $0.45(1.4)$ & $29.1(90.6)$ & $2.2(6.9)$ & 32.1 & 29.6 \\
\hline$M-3^{a}$ & $0.85(2.3)$ & $0.48(1.3)$ & $31.8(87.6)$ & $2.5(6.9)$ & 36.3 & 28.5 \\
\hline$Y-1^{b}$ & $0.010(0.9)$ & $0.0024(0.2)$ & $1.01(90.9)$ & $0.085(7.6)$ & 1.11 & 1.28 \\
\hline $\mathrm{Y}-2^{\mathrm{b}}$ & $0.033(1.2)$ & $0.0025(0.1)$ & $2.44(90.7)$ & $0.218(8.1)$ & 2.69 & 2.70 \\
\hline$Y-3^{b}$ & $0.153(2.9)$ & $0.0024(0.04)$ & $4.63(89.6)$ & $0.385(7.4)$ & 5.17 & 5.44 \\
\hline $\mathrm{K}-1^{\mathrm{c}}$ & $6.27(2.7)$ & $4.81(2.1)$ & $197(86.1)$ & $20.7(9.1)$ & 229 & 257 \\
\hline $\mathbf{K}-2^{\mathbf{c}}$ & $2.71(1.8)$ & $2.11(1.4)$ & $138(90.7)$ & $9.37(6.2)$ & 152 & 164 \\
\hline$K-3^{c}$ & $2.42(3.2)$ & $0.82(1.1)$ & $69.9(91.5)$ & $3.25(4.3)$ & 76.4 & 70.9 \\
\hline
\end{tabular}

a. Taken in Minamata Bay in 1983. b. Taken in Yatsushiro Sea in 1975. c. Taken at the sea bottom near the submarine fumaroles in Kagoshima Bay in $1977-1978$. d. Figure in the parentheses indicate \% values vs. sum of $4 \mathrm{values-org} \cdot \mathrm{Hg}, \mathrm{HgO}$, $\mathrm{HgS}$ and rsd·Hg. e. Obtained by Procedure-tot $\cdot \mathrm{Hg}$.

$-\mathrm{HgO},-\mathrm{HgS}$ and $-\mathrm{rsd} \cdot \mathrm{Hg}$ agreed well with that for the total mercury obtained by Procedure-tot $\cdot \mathrm{Hg}$. The total mercury contents in the samples taken from Minamata Bay were comparable to those reported previously. ${ }^{8}$ As was expected from the anaerobic condition of sediments and the chalcophilic property of mercury, about $90 \%$ of the mercury in marine sediments existed as mercury(II) sulfide. The values as mercury(II) oxide obtained by Procedure-HgO may contain those being due to acid soluble inorganic species of mercury, such as mercury(II) chloride, other than oxide. Although it is not easy to elucidate the chemical forms of the acid soluble inorganic mercury species, the speciation is an interesting subject to be further investigated.

We are indebted to Dr. Tadashi Fujisaki of The National Institute For Minamata Disease for providing the samples of marine sediments in Minamata Bay.

\section{References}

1. M. Fujiki, Bunseki Kagaku, 19, 1507 (1970).
2. S. Nishi, Y. Horimoto and Y. Umezawa, Bunseki Kagaku, 19, 1646 (1970).

3. Y. H. Lee and K. Mowrer, Anal. Chim. Acta, 221, 259 (1989).

4. S. Nishi and Y. Horimoto, Bunseki Kagaku, 17, 1247 (1968).

5. Y. Umezaki and K. Iwamoto, Bunseki Kagaku, 20, 173 (1971).

6. E. Munaf, H. Haraguchi and D. Ishii, Anal. Chim. Acta, 253, 399 (1990).

7. M. Filippelli, Anal. Chem., 59, 116 (1987).

8. K. Tajima, F. Kai and Y. Osajima, Nippon Kagaku Kaishi, $1985,976$.

9. H. Sakamoto and M. Kamada, Nippon Kagaku Kaishi, 1981, 32.

10. H. Sakamoto and M. Kamada, Rep. Fac. Sci. Kagoshima Univ. (Math. Phys. Chem.), (13), 63 (1980).

11. See, e.g., "Teishitsu Chosahoho to Sono Kaisetsu (Handbook of Sediment Investigation, in Japanese)", ed. Environment Agency, p. 14, Nippon Kankyo Sokutei Bunseki Kyokai, Tokyo, 1977.

(Received September 24, 1991) (Accepted December 18, 1991) 